\title{
De costas para a América, de frente para a Europa: a orien- tação da política externa do Imperio do Brasil
}

\author{
De espaldas a América, de cara a Europa: la orientación de \\ la política externa del Imperio de Brasil
}

\section{Ignoring the Americas, looking to Europe: the foreign policy of the brazilian Empire}

\author{
José Augusto Ribas MiRAnda \\ Instituto Brasileiro de Mercado de Capitais (Brasil) \\ jose.miranda@ibmec.edu.br
}

Fecha de recepción: 25-06-2018

Fecha de aceptación: 30-01-2019

\section{RESUMO}

O presente artigo apresenta um balanço da orientação da política externa do Império do Brasil (1822-1889). Como monarquia e com laços dinásticos com a Europa, o Brasil projetou uma política externa mais voltada à cortes europeias do que às salas presidenciais latino-americanas. A isso se devem as bases legitimadoras da monarquia brasileira e das repúblicas hispânicas e a visão de civilização e monarquia presente na elite imperial brasileira. Para demonstrar a orientação europeia da política externa brasileira, foram elaborados gráficos e tabelas dos funcionários do Itamaraty e suas respectivas gradações hierárquicas locados nos países com os quais o Império possuía representação diplomática.

Palavras-Chave: Política Externa, Império do Brasil, Monarquia, Diplomacia.

Topónimo: Brasil, América Latina.

Período: século XIX

\section{RESUMEN}

El presente artículo presenta un balance de la orientación de la política exterior del Imperio de Brasil (1822-1889). Como monarquía y con vínculos dinásticos con Europa, Brasil proyectó una política exterior más orientada a las cortes europeas que a las salas presidenciales latinoamericanas.

\footnotetext{
* Este artigo é uma versão remodelada de parte da dissertação de mestrado "Diplomata mais amante do seu paiz que das suas commodidades: a atuação de Francisco Adolfo de Varnhagen nas repúblicas do Pacífico (1863-1865)" defendida na Pontifícia Universidade Católica do Rio Grande do Sul em agosto de 2013 financiada com bolsa CNPq/Brasil.
} 
A esto se deben las bases legitimadoras de la monarquía brasileña y de las repúblicas hispánicas y la visión de civilización y monarquía presente en la elite imperial. Para demostrar la orientación europea de la política exterior brasileña, se elaboraron gráficos y tablas de los funcionarios de Itamaraty y sus respectivas gradaciones jerárquicas ubicadas en los países con los que el Imperio poseía representación diplomática.

Palabras clave: Política Exterior, Imperio de Brasil, Monarquía, Diplomacia

Topónimos: Brasil, América Latina

Período: siglo XIX

\section{ABSTRACT}

This paper presents an assessment of the Brazilian Empire's foreign policy (1822-1889). As a monarchical regime with strong ties with the European monarchies, Brazil structured a far more European-oriented foreign policy, attributing less importance to her Latin American neighbours. This explains the legitimising foundations of the Brazilian monarchy and the Hispanic republics and the imperial elite's vision of civilisation and monarchy. To illustrate the European orientation of Brazilian foreign policy, the paper includes graphs and tables in relation to civil servants and their hierarchical ranking in countries where the Brazilian Empire had a diplomatic presence.

Key words: Foreign Policy, Brazilian Empire, Monarchy, Diplomacy

Place names: Brazil, Latin America

Period: $19^{\text {th }}$ Century

\section{INTRODUÇÃO}

O presente artigo propõe uma análise das relações entre o Império do Brasil e seus vizinhos republicanos durante o período inicial de consolidação destes Estados e do surgimento de uma política interamericana. Já no primeiro Congresso das Nações Americanas no Panamá em 1826 notamos a relação peculiar entre a monarquia de origem portuguesa e as repúblicas de origem espanhola. Presidido por Simón Bolívar, o Congresso do Panamá não contou com a participação do Brasil, e ainda revelou a desconfiança das repúblicas envolvidas para com a manutenção da monarquia dos Bragança em solo americano, na pessoa do Príncipe Regente, agora Imperador do Brasil, D. Pedro I .

Passados os momentos iniciais, a política externa brasileira encontrou um caminho tortuoso para relacionar-se com uma América do Sul hispânica e republicana. Para além dos conflitos armados nas décadas de 1820 (Guerra da Cisplatina e bloqueio ao porto de Buenos Aires), dos anos 1850 (guerra contra o ditador argentino Juan Manuel de Rosas e as intervenções no Uruguai) e da Guerra da Tríplice Aliança em 1865-1870, as negociações de fronteiras também apresentavam um constante ponto de atrito entre o Brasil e seus vizinhos, com limites territoriais definidos somente nas primeiras décadas do século XX (Bandeira, 1998).

Com um cenário pouco otimista, o Império do Brasil desenhou sua política externa voltada para a Europa e de costas para a América. A aproximação ideológica com os regimes monárquicos europeus e uma autoimagem de nação europeia e civilizada das elites

1 A desconfiança passava pelos medos que estes países possuíam de o Brasil tornar-se um instrumento da Santa Aliança para restaurar o domínio espanhol no continente. A relação complicada nos momentos iniciais entre os primeiros libertadores e a emergente monarquia brasileira é trabalhada em profundidade na obra de Seckinger (1984). 
brasileiras forneceu os elementos da formação da política externa do Itamaraty durante os primeiros quarenta anos da atividade diplomática. Com o gradual envolvimento do Brasil com a geopolítica regional e a constante busca pela primazia na região da bacia do Prata, o Império começou na década de 1870 uma lenta reorientação de sua política externa em direção à América do Sul.

Essa orientação da política externa do Império do Brasil é o foco deste artigo. Para demonstrar a orientação e lenta reorientação da atuação do Itamaraty no cenário internacional, foram construídos gráficos e tabelas com a quantidade de legações diplomáticas brasileiras nas cortes europeias e gabinetes sul-americanos. Também foram observadas as quantidades de diplomatas e funcionários alocados nestas duas regiões, ilustrando um quadro de primazia europeia e lenta reorientação latino-americana nos 66 anos de existência da monarquia brasileira. Antes, realizo um debate sobre as bases legitimadoras e as origens da conceitualização da política externa imperial, ponto basilar para a compreensão dos dados apresentados e dos lentos movimentos de orientação dessa política externa ao longo da segunda metade do século XX.

\section{AS BASES LEGITIMADORAS}

A relação do Império do Brasil com seus vizinhos republicanos desenvolveu-se ao longo do século XIX de maneira delicada e, de certa forma, desconfortável. A assimetria entre os regimes e as respectivas crenças de superioridade de suas instituições tornavam as relações diplomáticas entre as ex-possessões lusa e espanhola na América sôfregas, apesar de desejáveis ${ }^{2}$. Grande parte das dificuldades subjacentes a tais relações baseia-se em dois postos-chave: 1- diferença de base legitimadora dos regimes e 2- processos de independência.

As independências da América espanhola foram motivadas pela urgência da manutenção de uma ordem política interna coesa. Com as invasões napoleônicas na península ibérica e a queda do monarca Bourbon Fernando VII em inícios do século XIX, as bases legitimadoras do império espanhol foram colocadas em xeque. Contando com uma população majoritariamente mestiça e indígena, as elites criollas na América necessitavam de uma solução para manter o status-quo da ordem política e econômica. A queda do princípio norteador monárquico, alimentado por duzentos anos de colonização, abriu um vácuo perigoso de legitimação política, necessitando de respostas rápidas e adequadas para as mais distantes unidades administrativas imperiais. Neste intuito, as elites criollas buscaram uma base legitimadora com um projeto nacional republicano e constitucional para restaurar conceitualmente a legitimidade da estrutura de poder interna da sociedade colonial (Damas, 2003: 41).

Ao tempo das lutas armadas nas décadas de 1810 e 1820 as opções políticas para a construção dos Estados variavam desde as propostas extremas, como monarquias absolutas ou repúblicas jacobinas, às alternativas moderadas, como o modelo monárquico-constitucional e o republicano de inspiração norte-americana. As alternativas radicais foram peremptoriamente excluídas, sendo o caminho moderado preferível. Garantir a propriedade privada e a manutenção do poder político pela classe dominante, conciliados com um regimento civil igualitário e prevenção da arbitrariedade e opressão do Estado eram prioridades paras tais elites criollas. As liberdades experimentadas pelas colônias no período de

2 Nos debates no parlamento ainda na década de 1830 deputados e senadores urgiam por uma maior aproximação política com as repúblicas sul-americanas, como expressou o deputado Lino Coutinho da resposta à Fala do Trono de 1830: "[...] que o governo fosse ainda mais solícito em estreitar estes laços com os novos Estados da América." (Brasil, 1977: 129). 
ocupação francesa na metrópole, seguidas pelo recrudescimento absolutista com a volta de Fernando VII ao poder contribuíram para a erosão da imagem do regime monárquico e o seu conseguinte descarte. Assim, por aproximação, o modelo republicano tornou-se o mais satisfatório, além de afastar o espectro monárquico recém-combatido (Damas, 2003: 42).

As repúblicas hispano-americanas saudaram sua independência política buscando construir uma base legitimadora de cunho nacional, em condicionamentos essencialmente locais, obedecendo ritmos desiguais. A dificuldade em constituir um princípio nacional agregador teria levado, portanto, as repúblicas hispano-americanas às mais variadas vicissitudes políticas e dissensões internas. O próprio sonho bolivariano de uma América espanhola grande e unida curvara-se ante as intempéries políticas regionais que deflagraram seu fracionamento em várias unidades políticas distintas. Com o avanço de um nacionalismo/ patriotismo político criollo, a rede de relações de lealdades cimentadas pela devoção religiosa ao monarca foi substituída por essa nova ideia de comunidade.

A criação de "comunidades imaginadas"3 na América espanhola foi fruto de um longo processo que derivou da substituição do referencial dinástico no monarca absoluto metropolitano por referenciais locais, sob a liderança das elites criollas. Ou seja, o processo emancipatório de matriz militarista calcado na fragmentação das unidades administrativas espanholas pela guerra inviabilizou qualquer tipo de permanência nas bases legitimadoras do Império espanhol, como coloca Damas:

Para tentar combater os efeitos negativos da perda do tradicional foco de legitimidade sobre as estruturas de poder no interior das sociedades, ao desconhecer-se a autoridade real, e a desarticulação do poder colonial, tanto na administração quanto na justiça, as nascentes sociedades republicanas contavam somente com os militares e a Igreja (Damas, 2003: 35).

Com o deflagrar dos conflitos entre as colônias e a Coroa espanhola, um forte sentimento anti-peninsular pairava sobre as elites criollas. Era preciso diferenciar-se da Europa e da Espanha. A América seria o novo mundo, livre dos vícios que degredavam os espíritos e instituições do velho continente, livre da monarquia. Essa aproximação a um novo modelo possuía forte inspiração na revolução americana de 1776. A nova ordem, republicana e americana, emergia tanto na geopolítica global quanto no discurso político da época. Thomas Jefferson delineou sua visão de "hemisfério americano" em cartas nos anos de 1808, 1809 e 1811, apregoando uma natural aproximação dos povos deste continente: aproximados tanto pelos novos "modos de vida" quanto pela orientação constitucional republicana. O "hemisfério americano", delineado por Jefferson emergia anos antes das guerras de independência de seus vizinhos e seria repercutido como arcabouço ideológico, fundamentador do republicanismo (hispano) americano. O modelo de Europa da restauração pós-guerras napoleônicas (monárquico, absolutista) pouco interessava às repúblicas hispânicas (Vázquez, 2003: 505).

No caso luso-americano, a manutenção dos laços dinásticos entre Portugal e Brasil legou ao Império uma imagem europeia, representada pela manutenção do regime monárquico. O Reino Unido de Portugal Brasil e Algarves de 1815 americanizara um pedaço da Europa, ao passo que europeizara grande parte da América do Sul. O Brasil, ao contrário

3 Benedict Anderson cunha este conceito para refletir sobre as nações e os nacionalismos. Para o autor, o nacionalismo nas Américas teria sido fruto de um processo de aceleração do capitalismo tipográfico e da circulação de agentes imperiais espanhóis. Sobre esta frágil base nacional teriam as elites criollas dado cabo da construção de suas comunidades imaginadas, produzindo conflitos internos por quase todo o século XIX (Anderson, 2008). 
de seus vizinhos republicanos, participaria do "sistema europeu", tendo sua independência negociada nas cortes europeias frutificando em casamentos reais (D. Pedro I e Dona Leopoldina, arquiduquesa de Áustria) e compromissos de cunho dinástico (Manchester, 1973: 165). A questão "nacional" não era tão vital para o Brasil, uma vez mantidos os laços dinásticos como base legitimadora. O Império comungava da mesma situação dos estados europeus, que só foram ater-se consideravelmente para um princípio nacional de formação do Estado após as insurreições de 1848. O Império do Brasil forjara-se em seu período inicial, portanto, nos moldes europeus, de amálgama dinástica e estatal, não nacional. Ao pensar nas monarquias europeias, Hobsbawm afirma:

Um patriotismo puramente baseado no Estado não é necessariamente ineficaz, desde que a própria existência e funções do Estado-cidadão territorial moderno constantemente envolva os habitantes em seus assuntos e, inevitavelmente, forneça uma "paisagem" institucional e processual diferente de todas as outras e que seja o cenário de suas vidas, por ele amplamente determinadas (Hobsbawm, 2011: 100 Grifo meu).

As funções do Estado-cidadão foram gestadas pelas elites brasileiras, encontrando na monarquia constitucional seu alicerce. Kirsten Schultz (2006) reitera que a opção do Brasil em adotar um regime monárquico-constitucional coadunava com o sentimento americano de liberdades e libertação do julgo opressor absolutista, porém com uma receita mais moderada, com sotaque do constitucionalismo das cartas liberais de 1791 (França), 1812 (Espanha) e 1822 (Portugal), tendo em vista as experiências detratoras da França jacobina e das lutas fratricidas na América espanhola (Schultz, 2006: 146).

Nesse sentido, o Brasil gozava de uma paisagem institucional monárquica diferente das propostas nacionais almejadas pelas repúblicas hispano-americanas, amalgamadora da unidade territorial e formadora do Estado. Seu processo de emancipação fora realizado na manutenção das instituições monárquicas sob a égide de um príncipe europeu. O novo Império americano contou, portanto, com a permanência do regime monárquico e da escravidão, legando ao país uma base política de legitimação dinástica no que Santos chamou de modelo europeu "Estado-territorial e dinástico, depois Estado-nação". (Santos, 2004: 38).

No caso brasileiro, a vinda da família real em 1808 provocou o aprofundamento dos laços entre colonos e reinóis, transmutando para a América o cerne do Estado português. A transferência da corte portuguesa para o Rio de Janeiro, com toda sua pompa e simbolismos, amalgamou os interesses de reinóis e colonos, colocando estes mais próximos ao rei, em um processo intenso de assimilação das bases legitimadoras monárquicas. Nunca um monarca fora tão pródigo com seus súditos, e a distribuição de títulos e comendas aos súditos brasileiros amarrou a elite fluminense ao pé do trono, embevecendo-os com os símbolos e ritos da monarquia absoluta. Este enraizamento e naturalização da monarquia pelas elites dirigentes do Rio de Janeiro frutificou em uma disposição em manter o regime, sob os auspícios do príncipe Bragantino (Malerba, 2000). Com isso, a base legitimadora do estado brasileiro seria garantida pela instituição monárquica, instituição esta que contributiva para a manutenção da unidade territorial da ex-possessão portuguesa na América.

Norbert Elias (1996) aborda o processo civilizador vivido pelos nascentes Estados europeus a partir do século XIII. Com a gradual centralização dos poderes e o monopólio da violência passando para as mãos do Estado, as condutas sociais e políticas, passaram para um novo estágio de controle e regulação. A maior interdependência entre os estratos sociais produzia relações mais moderadas, e o Rei era seu regulador. A todas estas mudanças Elias chama de "processo civilizador". Para o autor, o ocidente (Europa) alcançou níveis de monopólio da força e tributação, divisão de funções, interdependência e competi- 
ção inigualáveis, compondo as características de uma conduta que passou a ser conhecida como civilizada (Elias, 1996: 207). Assim, a Europa e o "sistema europeu" passaram a ser o referencial de civilização.

Se os Estados europeus eram o referencial de civilização, também suas instituições monárquicas gozavam deste status. Todavia, a instituição fora "renovada" agregando valores do constitucionalismo de aporte iluminista no contexto do fim do século XVIII e inícios do XIX (Lynch, 2009: 150). A tradição legalista portuguesa, originária dos códigos afonsinos ainda do século XIV, produziu uma cultura contratual de forte enraizamento na paisagem institucional da monarquia portuguesa. A opção das elites brasileiras pela assinatura de uma constituição, ainda que outorgada pelo Imperador, corresponde a essa longa tradição em uma mescla de letra da lei e vontade do monarca. O próprio D. Pedro I que viria a outorgar a carta constitucional brasileira de 1824 seria conhecido como D. Pedro IV em Portugal, defensor do regime constitucional contra os achaques de seu irmão absolutista D. Miguel. Essa cultura constitucional amalgama-se ao pendor civilizacional que o regime monárquico legou às instituições brasileiras, tornando as elites mais orientadas ao farol constitucional monárquico-europeu do que às chamas revolucionárias republicanas de seus vizinhos hispano-americanos (Paquette, 2018: 46-47).

A ligação entre monarquia e civilização passou por um processo de fortalecimento e sedimentação durante o período das revoltas regenciais do Império do Brasil. Vencidas as vicissitudes, a opção monárquica agregava, para as elites imperiais, valores positivos como "interesse público" e "bem comum." (Starling; Lynch, 2009: 240). A monarquia constitucional seria a tábua de salvação para o país, evitando o republicanismo anárquico das repúblicas hispano-americanas, e o absolutismo arcaico europeu. Como afirmava o Marquês de Caravelas na Assembleia Constituinte de 1823, a monarquia constitucional era: "[...] o único governo capaz de fazer a felicidade e a prosperidade das nações; porque marchando a honra com a civilização, e com as luzes do século, é o único que oferece a tríplice aliança da força, da sabedoria e da liberdade" (Starling; Lynch 2009: 232).

Desta feita, o Império do Brasil dividia-se entre a Europa e América. Sua identidade política era construída com base em aproximações aos modelos europeus e como anti-exemplo da América espanhola, considerada bárbara e anárquica. A concepção de superioridade do regime monárquico marcava a institucionalidade imperial brasileira, que mesmo escravista e distante da Europa se colocava, dentre os bárbaros regimes latino-americanos, como o mais civilizado.

Estas diferentes bases de legitimação dos regimes entre o Império e as repúblicas vizinhas contribuíram para uma delicada relação política, dada a singularidade do Brasil no cenário sul-americano. Assim, apesar da tendência de maior integração no cenário político americano, a política externa imperial ainda voltava-se mais à Europa e menos à América.

\section{DE FRENTE PARA A EUROPA, DE COSTAS PARA A AMÉRICA.}

Para o Império do Brasil, uma política continental verdadeiramente americanista se colocava de maneira delicada, uma vez que arriscaria sua identidade monárquica, europeia e civilizada. Precisava manter seus laços fortes com a Europa tendo em vista constituir esta imagem. De fato, durante boa parte do século XIX o império mantivera na Europa um "corpo diplomático tão suntuoso" nas palavras do senador Francisco de Paula Souza e Melo em $1846^{4}$. Todavia, as urgências e vicissitudes locais implicavam em uma necessidade maior de lidar com seus vizinhos no tocante as questões de fronteiras e navegação fluvial.

4 Atas do Senado, 29 de agosto de 1843, p. 628. 
Apesar do crescimento e da urgência pelo fortalecimento das relações entre o Império e as repúblicas americanas entre as décadas de 1830 a 1880, a atividade diplomática do Império com as monarquias europeias manteve-se mais efetiva em representações diplomáticas e em considerável superioridade no número de funcionários em tais legações. A própria organização das secretarias internas do Itamaraty após as complicadas insurgências das décadas de 1830 e 1840 demonstrava como se priorizava a política externa do Segundo Império, dividida em quatro seções: Um seção para os assuntos em Londres e Paris; uma seção para brasileiros na Europa e europeus no Brasil, uma seção para brasileiros na América e americanos no Brasil; e uma seção para assuntos contábeis ${ }^{5}$. Esta divisão já prenuncia a pouca atenção recebida pelos vizinhos de "hemisfério americano", que viria a mudar lentamente a partir da década de 1870, como explanado mais adiante.

Para analisar essa orientação da diplomacia brasileira no período imperial, apresento abaixo dois gráficos e um quadro com dados retirados dos relatórios anuais do Ministério dos Negócios Estrangeiros, apresentados ao parlamento no fim do ano orçamentário (junho). Esses relatórios apresentam o corpo diplomático brasileiro alocado nas legações do exterior e o corpo diplomático estrangeiro presente no Brasil. Para tal, foram selecionados os relatórios relativos aos anos de 1830, 1840, 1850, 1860, 1870, 1881 para traçar um panorama da orientação diplomática durante o período de duração do Império. Foram elaborados dois gráficos e um quadro: O gráfico I apresenta o número de legações brasileiras no exterior; O gráfico II apresenta o número de funcionários alocados nas legações brasileiras no exterior, desconsiderando funcionários de consulados fora das capitais ${ }^{6}$; No quadro I, a distribuição dos funcionários por continente (Europa e América) de acordo com o cargo na hierarquia diplomática, do mais elevado, ministro plenipotenciário (ou enviado extraordinário) ao mais baixo, adido.

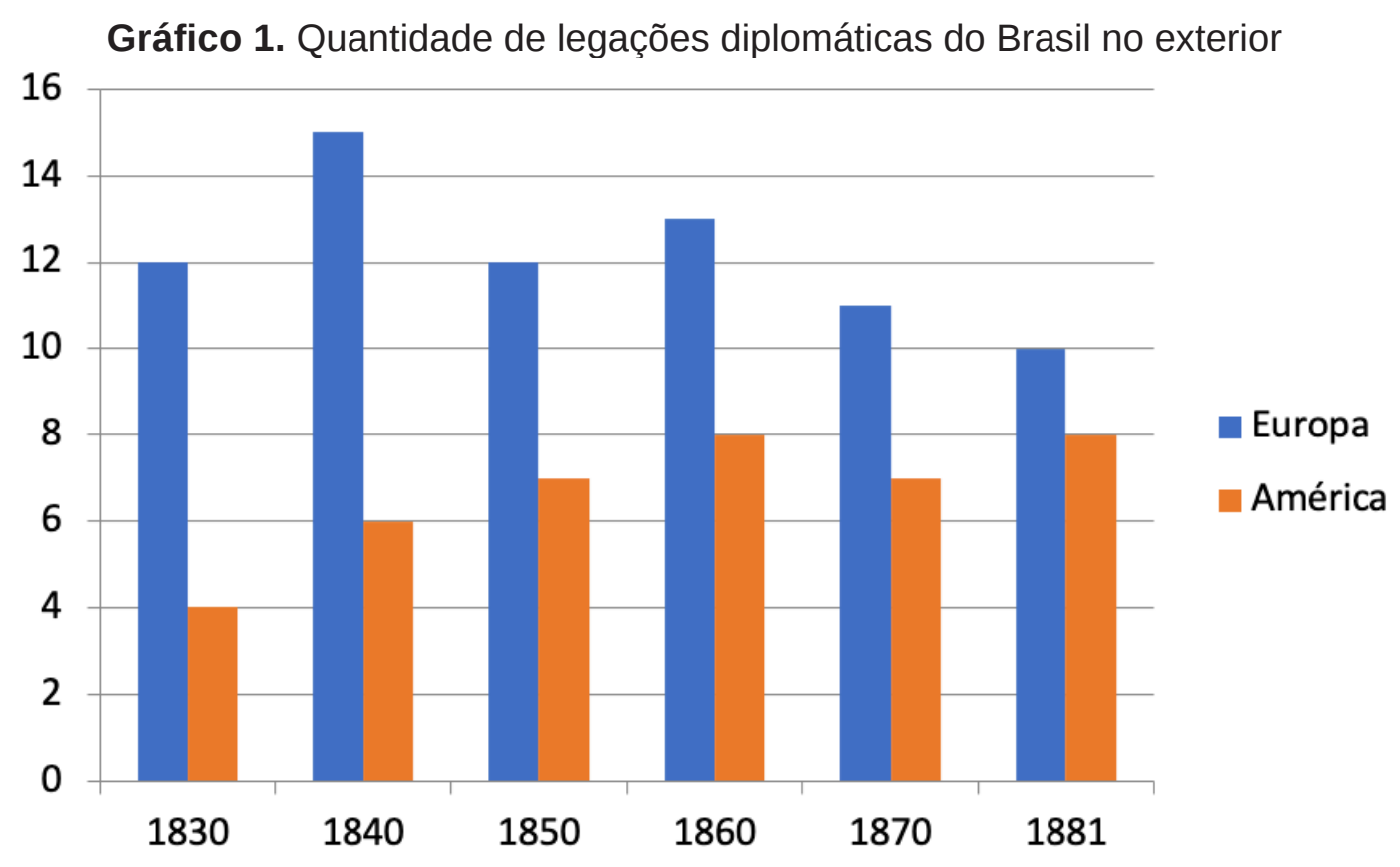

Fonte: Elaboração própria a partir de Relatório do Minisério dos Negócios Estrangeiros 1830-1881.

5 Relatórios do Ministério dos Negócios Estrangeiros, 1857, p. 3.

6 Os consulados foram considerados apenas em países que não possuíssem uma legação diplomática, como no caso do consulado em Buenos Aires em 1830. Por tratarem majoritariamente de assuntos de caráter civil, e não questões de Estado, os consulados foram, nos demais casos, desconsiderados dos gráficos. 
Gráfico 2. Quantidade de funcionários e representantes diplomáticos do Brasil no exterior

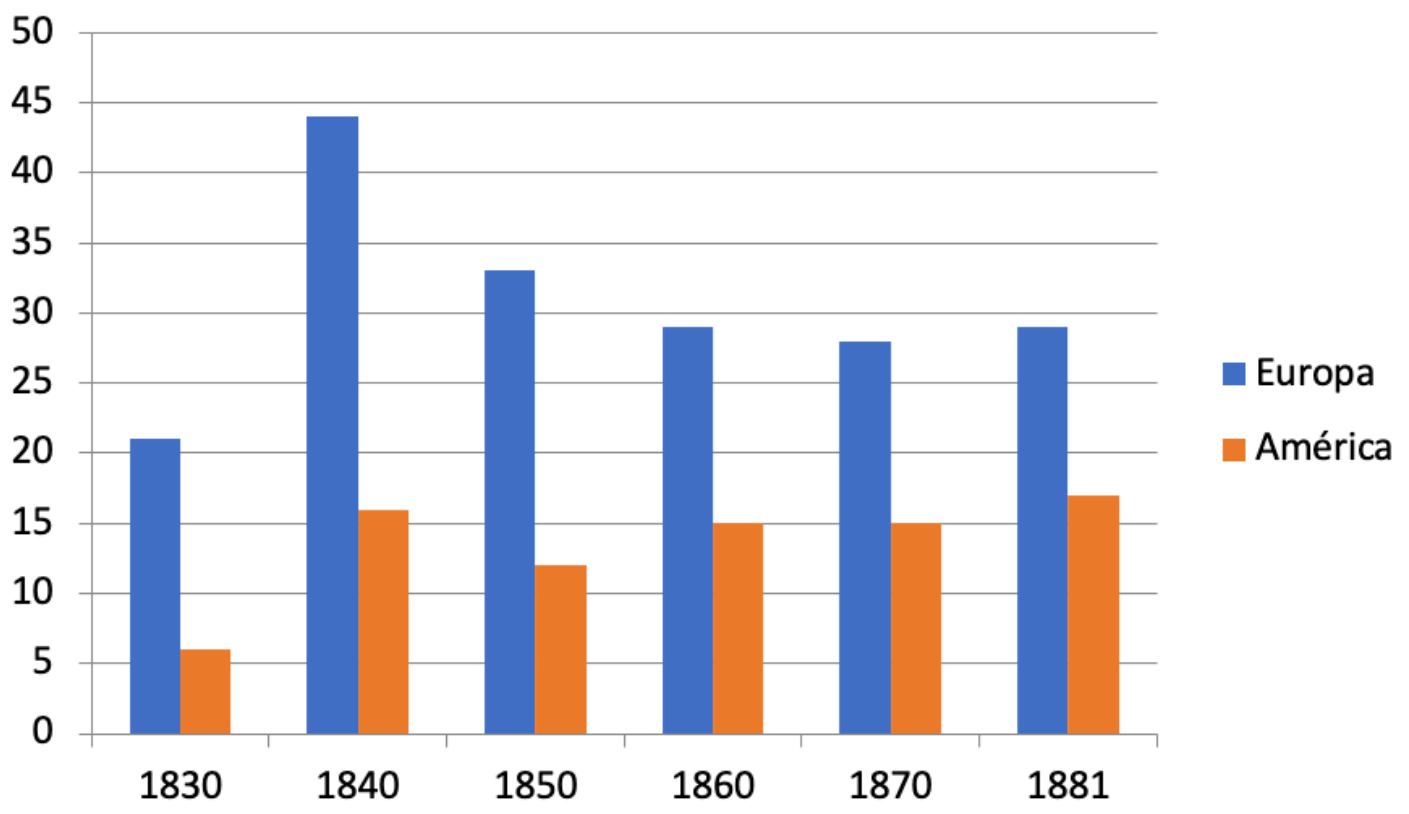

Fonte: Elaboração própria a partir de Relatório do Minisério dos Negócios Estrangeiros 1830-1881.

Quanto às legações diplomáticas na Europa é necessário considerar que as unificações do Reino da Itália na década de 1860 e do Império Alemão na década de 1870 acarretaram uma queda esperada no número de postos alocados, devido a fusão de legações, como as do Reino de Sardenha e Reino das Duas Sicílias no caso italiano, e da Prússia, cidades hanseáticas e demais ducados no caso alemão. Todavia, a diferença no número de representantes e funcionários diplomáticos manteve-se grande no período. A relação entre o número de legações diplomáticas o número de Estados na Europa e América também deve ser considerada.

Mesmo com a progressiva queda na diferença do número de legações diplomáticas do Brasil na Europa e na América, o quadro de representantes e funcionários (e os consequentes gastos) apresenta uma considerável disparidade entre os dois cenários, demonstrando uma aberta prioridade do Império do Brasil na manutenção das relações para com as monarquias europeias, alocando representantes diplomáticos de alto escalão (enviados extraordinários e ministros plenipotenciários) em reinos com os quais possuía mais interesses dinásticos que interesses políticos e comerciais, como em Áustria, Bélgica, e Itália (Estados Italianos antes de 1860), contando com representatividade diplomática durante todo o período de duração do Império. Outro dado relevante foi o rebaixamento da legação diplomática em França no início da década de 1850 quando da ascensão da II República, em que o representante máximo consistia em um encarregado de negócios - terceiro cargo na hierarquia representativa. No início década seguinte, em pleno Império de Napoleão III, a representação brasileira voltaria a contar com um ministro plenipotenciário.

Há uma sensível diferença entre a representação diplomática na Europa e na América. Com a Europa, as relações comerciais eram sim de maior peso, mas a quantidade de funcionários e legações em países sem expressão política e econômica para com o Império chama a atenção. As legações diplomáticas brasileiras no Império Russo e nos reinos de Suécia, Dinamarca e Noruega, por exemplo, sempre contaram, com, no mínimo, encarregados de negócios e mesmo ministros plenipotenciários desde a década de 1830. 
Parte deste esforço por representatividade política nas cortes europeias é tributária da própria herança diplomática portuguesa. Durante as negociações do Congresso de Viena de 1815, Portugal obrou ativamente para manter-se como participante ativo na nova ordem internacional pós-napoleônica, um esforço que envolvia negociações diretas entre Espanha, Áustria, e territórios italianos (Comiran, 2018). O Brasil já fazia parte como elemento constituinte do recém elevado Reino Unido de Portugal Brasil e Algarves (1815) e a prática e traquejos diplomáticos lusos deixaram espaços após o rompimento em 1822, rapidamente ocupados por diplomatas brasileiros treinados à moda portuguesa tanto nas lidas diplomáticas lisboetas quanto nos bancos universitários de Coimbra (Malerba, Miranda, 2014).

Tendo em vista o processo de emancipação do Império, a necessidade de uma alta representatividade na Europa, em busca de reconhecimento político, se fazia necessária. Todavia, o processo de reconhecimento da independência do Brasil pelas potências europeias perdurou até a década de 1840 (Manchester, 1973: 178), quando se observa o ápice de funcionários alocados na Europa, presente no gráfico II. A partir de 1860 a diferença de proporção de funcionários alocados na Europa e América permanece praticamente a mesma até o ano de 1881, indicando que a suntuosidade do corpo diplomático na Europa mantivera-se a despeito de um maior entrelaçamento às questões americanas. O próprio casamento de D. Pedro II em 1842 demonstrou dois aspectos importantes: o primeiro deles foi a importância dada às relações europeias, consideradas políticas, dinásticas e civilizacionais. A isso os altos custos do envio de Bento Lisboa às cortes europeias em 1840 e os valiosos presentes dispensados à Teresa Cristina (que impactaram as rodas aristocráticas do velho mundo, que sempre creditavam o Império tropical de exótico e pobre) revelam este firme interesse em construir uma imagem civilizada e europeia. Outro ponto que o casamento revelou foi o baixo retorno desse investimento em uma projeção europeia e civilizada, quando o máximo que D. Pedro II conseguiria seria um matrimônio com uma princesa do ramo pobre dos Bourbons de Nápoles, periferia aristocrática da Europa. (Schwarcz, 1999: 91-100).

A título de comparação, os Estados Unidos só foram receber um ministro plenipotenciário brasileiro na década de 1850, mesmo já representando o segundo maior destino das exportações brasileiras (Almeida, 2005: 84). Na América, mesmo que as relações econômicas também fossem baixas com a maioria dos Estados (Excetuando-se Estados Unidos, e os Estados da bacia do Prata), as pendências políticas e territoriais abundavam, urgindo questões de delimitação de fronteiras com nada menos que sete repúblicas (Uruguai, Paraguai, Argentina, Bolívia, Peru, Colômbia e Venezuela). O quadro abaixo mostra a distribuição dos cargos hierárquicos de ministro plenipotenciário, ministro residente, encarregado de negócios, secretários e adidos por região entre 1830 e 1880. 
Quadro 1. Graduação de representantes e funcionários do Brasil no exterior

\begin{tabular}{|c|l|c|c|c|c|c|c|}
\cline { 3 - 8 } \multicolumn{2}{c|}{} & $\mathbf{1 8 3 0}$ & $\mathbf{1 8 4 0}$ & $\mathbf{1 8 5 0}$ & $\mathbf{1 8 6 0}$ & $\mathbf{1 8 7 0}$ & $\mathbf{1 8 8 1}$ \\
\hline $\begin{array}{c}\text { Ministros } \\
\text { Plenipotenciários }\end{array}$ & Europa & 4 & 4 & 4 & 4 & 7 & 8 \\
\cline { 2 - 8 } & América & 1 & 1 & 2 & 1 & 4 & 3 \\
\hline \multirow{2}{*}{$\begin{array}{c}\text { Ministros } \\
\text { Residentes }\end{array}$} & Europa & 0 & 2 & 1 & 3 & 2 & 1 \\
\cline { 2 - 8 } & América & 0 & 1 & 0 & 3 & 1 & 2 \\
\hline \multirow{2}{*}{$\begin{array}{c}\text { Encarregados } \\
\text { de Negócios }\end{array}$} & Europa & 6 & 6 & 8 & 6 & 2 & 1 \\
\cline { 2 - 9 } & América & 2 & 4 & 5 & 3 & 1 & 3 \\
\hline \multirow{2}{*}{\begin{tabular}{c} 
Secretários \\
\cline { 2 - 8 }
\end{tabular}} & Europa & 3 & 6 & 5 & 5 & 5 & 6 \\
\cline { 2 - 8 } & América & 1 & 1 & 2 & 2 & 4 & 5 \\
\hline \multirow{2}{*}{ Adidos } & Europa & 3 & 15 & 15 & 11 & 12 & 13 \\
\cline { 2 - 8 } & América & 1 & 4 & 3 & 6 & 5 & 4 \\
\hline
\end{tabular}

Fonte: Elaboração própria a partir de Relatório do Minisério dos Negócios Estrangeiros 1830-1881.

O quadro acima apresenta uma maior presença de representantes de primeiro escaIão na Europa, enquanto que na América a maior parte da representatividade é feita por representantes de terceira e, logo após, de segunda ordem. A quantidade de secretários e adidos é relevante para a análise na medida em que quando as legações adquirem maior importância, Ihe são atribuídos um maior número de funcionários subalternos, destinados a organizarem e zelarem pela repartição. Vale ressaltar que a maior dificuldade de comunicação com as repúblicas vizinhas - as comunicações via navegação a vapor com a Europa eram mais bem estabelecidas - demandaria uma representatividade diplomática mais incisiva, com a presença de ministros plenipotenciários - mais autônomos em suas decisões. Todavia, isto não ocorria, e a presença diplomática brasileira nas repúblicas hispano-americanas obedecia a instâncias hierárquicas inferiores.

Desta feita, acompanhando a disparidade na quantidade de funcionários alocados nas legações diplomáticas do Império, a gradação dos representantes também revela um zelo maior pela política europeia, em detrimento do progressivo envolvimento do Brasil nas questões americanas e da equalização do número de legações diplomáticas entre os dois continentes ao longo do século. Durante o período apresentado, a presença de ministros plenipotenciários nas cortes europeias é em média 3 vezes maior que na América, enquanto que a presença de encarregados de negócios de ministros residentes, de menor importância diplomática, é similar.

Esta maior interação diplomática do Império do Brasil com os Estados europeus correspondia à similaridade de regimes, e, por outro lado, a rejeição aos regimes republicanos dos vizinhos hispânicos, considerados bárbaros e anárquicos. Ao reclamar deste quadro visivelmente euro-orientado, o deputado Lino Coutinho exclamaria na Câmara dos deputados na década de 1830 que "O nosso governo parece sentir um terror pânico só em ouvir pronunciar o nome de repúblicas"', delineando o quadro da ação diplomática brasileira para com Europa e América. 
Todavia, a tendência de crescimento da representação brasileira na América é inegável. O progressivo igualar no número de legações diplomáticas aponta para uma gradual reorientação da política externa imperial que toma força de programa de Estado com a derrubada da monarquia em 1889. Em inícios do século XX sob a batuta do Barão do Rio Branco, a política externa do Brasil se torna mais pragmática, dispensando o cortejo institucional às monarquias europeias como modo de validar o próprio regime. A mudança na orientação da política externa da república ganhou um forte símbolo no envio de Quintino Bocaiúva à Buenos Aires em 1890, carregado com pompa e circunstância por ataviadas embarcações na marinha nacional. Esse foi um esforço simbólico do governo republicano provisório de Deodoro da Fonseca para sinalizar a mudança na prioridade das relações externas da república, onde parceiros americanos e republicanos, como a Argentina, ganhariam o foco das atenções (Silveira, 2003).

\section{SUPERIORIDADE MONÁRQUICA COM ORIENTAÇÃO POLÍTICA}

À revelia dos objetivos diplomáticos, negociar com nações civilizadas era mais seguro e preferível. O exercício da alteridade política para com os Estados europeus dotaria 0 regime monárquico brasileiro, para suas elites dirigentes, de maior grau de civilização, credencial de superioridade institucional que acreditava gozar quando negociando com as repúblicas americanas. Como afirmava o Visconde do Rio Branco ao parlamento na década de 1870: "O governo imperial julga que o melhor meio de tornar as guerras menos fácies é procurar cercar-nos de povos civilizados, que com uma opinião pública de gente esclarecida e abastada possa influir nos respectivos governos"8.

Ao analisar as discussões parlamentares sobre a política externa do Império, encontra-se duas correntes orientadoras da ação brasileira. Nas relações fraco-forte, isto é, nas relações do Brasil para com as potências europeias e Estados Unidos, o apelo à razão, à civilização, ao direito internacional:

Para uma nação fraca como o Brasil, num mundo de poucos agentes internacionais, o do século XIX, porém de vínculos sempre mais intensos entre as nações, ${ }^{9}$ abrir espaço era uma dificuldade gigantesca. As vias da força e da concorrência, que comandavam a política externa das potências dominantes eram-Ihe inacessíveis. Escolheu, pois, a do direito, com todas as limitações que comporta, tão bem conhecidas pelos cientistas políticos. O direito contra a força, eis a concepção das relações fraco-forte, desenvolvida pelo pensamento político brasileiro no século XIX (Cervo, 1981: 15, Grifo meu).

Já para as repúblicas vizinhas, em especial da bacia do Prata, o governo imperial adotou um tom mais severo e intervencionista, desde a guerra da Cisplatina em 1828 até as os derradeiros atritos para com a república argentina no final do século. De fato, o Império preferia enviar missões especiais a manter um numeroso corpo diplomático para resolver as querelas mais importantes, como a missão Honório Hermeto Carneiro no Uruguai e Províncias Unidas do Prata em 1851-53, a missão Duarte da Ponte Ribeiro ao Peru, Bolívia Equador e Venezuela em 1851-52, a missão Varnhagen em substituição a Ponte Ribeiro em 1863-1865, a missão Saraiva no Uruguai em 1864 e a missão Paranhos no Paraguai em 1864-1865.

8 Ata da Câmara dos Deputados, 18 de agosto de 1874, vol. 4, pp. 402-505.

9 Por vínculos mais intensos não podemos deixar de considerar com vigor os laços dinásticos, plenamente aplicáveis ao Império. 
A América do Sul era o locus dos discursos anti-republicanos das elites brasileiras. Em 1844 aparece pela primeira vez o conceito "América do Sul" para referir-se ao lugar geopolítico das repúblicas vizinhas ${ }^{10}$. Até o México reconhecia uma forma inicial desta unidade, quando o ministro dos negócios estrangeiros mexicano Lucas Alamán se referia à América do Sul como Estados do Prata, Peru, Chile, Paraguai, Uruguai, excluindo o Império do Brasil e a Colômbia. (Santos, 2014: 67) A "América do Sul" volta a aparecer em 1855 nos mesmos relatórios até que na década de 1890, já após a instauração da república, o conceito encontra seu significado geopolítico atual.

A relação para com as repúblicas hispano-americanas operava em um sentido "paternal", de civilizado para bárbaro, tanto em momentos de neutralidade como de intervenção (Cervo, 1981: 53). Grande parte da superioridade arrogada ao Império pelos seus dirigentes advinha de sua estabilidade constitucional, fruto do sistema monárquico-representativo. As diferentes receitas políticas empregadas para o estabelecimento dos Estados nos processos pós-revolucionários comportavam uma ampla gama de disposições, cores e sabores regionais. O regime republicano fora adotado majoritariamente pelos novos Estados, saídos do império espanhol. Na parte lusa, o sistema monárquico emergiu, fruto de um processo peculiar de emancipação, conduzido por um processo que, em 67 anos de existência, contou com apenas uma constituição, a constituição brasileira de 1824.

O processo de construção dos Estados na América ibérica contou com uma generalizada onda constitucional. As nações recém-emergidas das monarquias absolutas experimentaram períodos de relativa liberdade política. O interregno espanhol, com a prisão do "desejado" Fernando VII, a imposição de José Bonaparte em 1808, e a vinda da corte portuguesa para sua possessão americana, com a elevação da mesma a título de Reino Unido em 1815 desembocaram nos processos constitucionais de 1812 (Espanha) e de 1822 (Portugal).

O constitucionalismo se apresentava como a porta de entrada para mundo civilizado aos Estados que então emergiam. Todos os novos países buscaram produzir e promulgar suas constituições, tema caro que os colocaria na "senda civilizacional", e os proporcionaria uma identidade política própria, tão necessária no período após as guerras de independência. O Ancien Régime ficara para traz na América, e os novos Estados buscavam sua inserção no novo escopo político predominante no ocidente. Assim, como coloca Hector Espiell (2003):

O constitucionalismo latino-americano inicial concebeu-se como uma expressão da civilização, como uma manifestação da recepção das novas ideias e como demonstração de que a América Latina passava a participar do pensamento filosófico e político do mundo moderno e civilizado, mediante a ordem constitucional (Espiell, 2003: 454).

De todo modo, este preceito constitucional, tão caro às elites dos Estados americanos, encontrou um tortuoso percurso ao longo do século XIX. Como dito anteriormente, o Império do Brasil contou com apenas uma constituição, sendo esta reformada duas vezes. Os temas polêmicos e até mesmo a integridade territorial do império passavam pela observância e, ao máximo, a reforma do texto constitucional. Não havia legalidade nem legitimidade em propostas e mudanças fora da orbita da constitucional. Nos debates parlamentares sobre o Poder Moderador na década de 1840 até mesmo os críticos de tal mecanismo, como o deputado Evaristo da Veiga e os senadores Paula de Sousa e Nicolau Vergueiro, se contorciam ante a legislação para fazer valer suas prerrogativas (Uruguai, 2002: 306-334).

10 Relatórios do Ministério dos Negócios Estrangeiros, 1844, p. 15. 
A permanência do texto-primeiro, adágio da inserção dos países no círculo das nações civilizadas, não contou com uma defesa intransigente nas repúblicas. Até o fim da década de 1870, a República da Bolívia havia gozado de nada menos que dez textos constitucionais; a República do Peru oito; República da Colômbia, cinco; República da Venezuela, três; as Províncias Unidas do Rio da Prata e a subsequente República Argentina, três. Até mesmo a centralizada República do Paraguai, com sua presidência perpétua e hereditária, passou por três distintas constituições (Espiell, 2003: 463).

Outro aspecto da repulsa aos regimes republicanos hispano-americanos pela elite imperial adivinha dos diferentes matizes da legitimação diferenciada entre os processos de independência das possessões espanhola e lusa. O longo processo de independência das ex-colônias espanholas foi calcado em combates e ações militares. O princípio de legitimação de tais independências contou, portanto, com uma base militarista marcante. Ansaldi (2003) identifica esta "militarização" da política nas nascentes repúblicas hispano-americanas, delineando um conjunto de processos em que "os pensadores ou ideólogos foram suplantados pelos militares" (Ansaldi, 2003: 411). Este suplantar não encontrou terreno na emancipação do Brasil. Contando com chefes de Estado monarcas, apenas três dos 32 gabinetes durante todo o império foram encabeçados por um militar ${ }^{11}$, mas mantendo estrito predomínio civil nas instâncias de governo. No Império do Brasil, a casaca submeteria a farda aos quadros de ferro da constituição e da ordem política monárquica, no que José Murilo de Carvalho chamou de "O Domínio dos Magistrados" (Carvalho, 2010).

Tal concentração de poder nas mãos dos líderes político-militares- os "chefes", "caudillos" -constituía o anti-exemplo de governo, de paz e estabilidade. Ou seja, eram sinônimos de república na América. Como vociferava o senador Alves Branco no parlamento em 1840:

Não argumentamos, porém, sobre esta base, porque senhores é impossível que possa haver um pensamento de crime na realeza, tal como está constituída entre nós; tais suposições só cabem aos chefes das repúblicas, aos Jacksons e outros, que, por agradarem à multidão frenética de que dependem, atacam as fortunas e créditos de seus concidadãos e do mundo inteiro: que monarca faria isto, senhores? Certamente nenhum (Uruguai, 2002: 326).

Essa "superioridade" que possuía o Brasil no cenário ibero-americano advinha, portanto, de seu anti-exemplo. A república, nas mentes e discursos das elites imperiais, era o antípoda da civilização. O caminho para tal, mais sereno, seguro e notável, havia de ser a monarquia, sistema herdado dos lusos, que mantinha, dentre outras coisas, vínculos indeléveis entre o Brasil e a Europa, credora do tão afamado status de civilização.

\section{CONCLUSÕES}

A política externa do Império do Brasil foi construída em torno do processo de legitimação de seu regime monárquico. A "planta exótica" semeada pelos portugueses desenhou uma política externa própria, tendo em vista as bases legitimadoras de seu regime e as questões geopolíticas sul-americanas mais prementes. Esse desenho legou uma maior importância da representação diplomática brasileira na Europa em comparação com seus vizinhos sul-americanos, que sofreu lento processo de reorientação somente a partir da década de 1870, finalizada somente após o advento do regime republicano pós 1889.

11 Luís Alves de Lima e Silva, o Duque de Caxias, ocupou a presidência do conselho de ministros em 1856 , 1861 e 1875. Para uma visão mais detalhada sobre o predomínio dos magistrados no establishment imperial brasileiro conferir (Malerba; Miranda, 2014). 
Para perceber essa orientação e seu lento processo de mudança, este trabalho apresentou os números e a alocação dos diplomatas brasileiros nas representações estrangeiras, presentes nos relatórios do Ministério dos Negócios Estrangeiros, que demonstrou dois pontos importantes. O primeiro deles é a primazia da política externa brasileira para com as cortes europeias. Mesmo em países de pouca representatividade econômica ou mesmo dinástica para o Brasil (como a distante Rússia ou Suécia) o Império manteve extensa representação diplomática com funcionários de alto escalão. Enquanto isso, países em que se consideraria maior a necessidade de representação diplomática devido às intensas relações comerciais (como os Estados Unidos) ou de fronteiras (como todos os demais sul-americanos), a alocação dos recursos, por meio de embaixadas e envio de funcionários de alto escalão, era limitada. O segundo ponto é a tendência de crescimento em importância das repúblicas hispânicas em representação diplomática, principalmente a partir do fim da guerra da tríplice aliança (1865-1870). Com o fim da guerra o Brasil passou a projetar-se como potencia regional, no que demandou maior atenção do Itamaraty, refletido no crescimento do numero de legações diplomáticas, de funcionários e da gradação dos enviados.

Essa orientação europeia da política externa brasileira era um reflexo da autoimagem que as elites imperais tinham e queriam para si: regime monárquico constitucional civilizado, um pedaço da Europa nas Américas. Até mesmo os republicanos brasileiros associavam Europa e monarquia, mas como opositores do regime descartavam a associação com a civilização, como bem descrito no afamado Manifesto Republicano de 1870:

Somos da América e queremos ser americanos. A nossa forma de governo é, em sua essência e em sua prática, antinômica e hostil ao direito e aos interesses dos Estados americanos. A permanência dessa forma tem de ser forçosamente, além de origem de opressão no interior, a fonte perpétua da hostilidade e das guerras com os povos que nos rodeiam. Perante a Europa passamos por ser uma democracia monárquica que não inspira simpatia nem provoca adesão. Perante a América, passamos por ser uma democracia monarquizada, onde o instinto e a força do povo não podem preponderar ante o arbítrio e a onipotência do soberano. Em tais condições, pode o Brasil considerar-se um país isolado, não só no seio da América, mas no seio do mundo (Moraes, 1977: 114).

Também o anti-exemplo das repúblicas hispânicas dava o tom da política do Itamaraty durante o período, em que reafirmar-se como monarquia alimentava a necessidade de representação diplomática nas cortes europeias, e essa representação reforçava o caráter civilizado, monárquico e anti-hispânico do regime imperial brasileiro. Apesar da lenta reorientação a partir da década de 1870, identificada pelo aumento de representatividade do corpo diplomático nos países americanos, foi com o advento da república em 1889 que a política externa teria seu processo de reorientação, da Europa às Américas, consumado. $O$ Império que nasceu de costas para seus vizinhos sul-americanos se tornaria a República engajada nas questões geopolíticas macrorregionais, como demonstrou a tradição diplomática brasileira com a demarcação de limites fronteiriços nas décadas de 1900 e 1910 e os contínuos projetos de integração regional ao longo do século XX e XXI como o ABC de Rio Branco, o Mercosul década de 1990 e a Unasul na década de 2000.

\section{FONTES CONSULTADAS}

Anais da Câmara dos Deputados: 1822-1889. Arquivo da Câmara dos Deputados, http:// imagem.camara.gov.br/diarios.asp?selCodColecaoCsv=A (Consulta: 12-12-2018)

Anais do Senado Imperial: 1830-1889. Arquivo do Senado, https://www.senado.leg.br/pu- 
blicacoes/anais/asp/IP_AnaisImperio.asp

Relatórios do Ministério dos Negócios Estrangeiros 1830-1890. Disponível Center For Research Libraries, http://ddsnext.crl.edu/brazil (Consulta: 12-12-2018)

\section{BIBLIOGRAFIA}

Anderson, B. (2006): Comunidades Imaginadas. São Paulo, Companhia das Letras.

Almeida, P. R. (2005): Formação da diplomacia econômica no Brasil. São Paulo, Editora SENAC; Brasília: FUNAG.

Ansaldi, W. (2003): "Unidad y diversidad en el pensamiento político" en Damas, G. C. (org.). Historia General de América Latina, Madrid, Ediciones UNESCO/Editorial Trotta, vol. 6, pp. 409-428.

Bandeira. L. M. (1998): O expansionismo brasileiro e a formação dos Estados na bacia do Prata, Brasília, Editora da UnB.

Brasil, Falas do Trono, Brasília, Instituto Nacional do Livro, 1977.

Carvalho, J. M. (2010): A construção da Ordem/ Teatro das Sombras. Rio de Janeiro, Civilização Brasileira.

Cervo, A. L. (1981): O parlamento brasileiro e as relações exteriores (1826-1889). Brasília, Ed. UnB.

Cervo, A. L. y Bueno, C. (2010): História da Política Exterior do Brasil, Brasília, Ed. UnB.

Comiran, F. (2018): A valsa dos pobres: o Congresso de Viena, os países ibéricos e a América Meridional, Tese de Doutorado, Pontifícia Universidade Católica do Rio Grande do Sul PUCRS, Porto Alegre.

Damas, G. C. (2003): "Del estado colonial al estado independiente nacional" en Vázquez, J. Z. (org.). Historia General de América Latina, Madrid, Ediciones UNESCO/Editorial Trotta, vol. 6, pp. 31-62.

Elías, N. (1996): O processo civilizador: Formação do Estado e Civilização, vol. II, Rio de Janeiro, Jorge Zahar Editor.

Espiell, H. G. (2003): "Constitucionalismo y codificación latinoamericanos: de la sociedad colonial a la sociedad republicana." en Damas, G. C. (org.). Historia General de América Latina, Madrid: Ediciones UNESCO/Editorial Trotta, vol.6, pp. 449-469.

Hobsbawm, E. J. (2011): Nações e nacionalismos desde 1780, Rio de Janeiro, Nova Fronteira.

Lynch, C. E. C. (2009): "Liberal/liberalismo" en Feres, J. Léxico da História dos conceitos políticos do Brasil, Belo Horizonte, editora UFMG, pp.141-160.

Lynch, C. E. C. y Starling, H. M. M. (2009): "República/Republicanos" en Feres, J. Léxico da História dos conceitos políticos do Brasil, Belo Horizonte, editora UFMG, pp. 225-245.

Malerba, J. (2000): A corte no exílio: civilização e poder no Brasil às vésperas da independência (1808-1821), São Paulo, Companhia das Letras.

Malerba, J y Miranda, J. A. (2014): "Expertise jurídica na construção do Estado monárquico no Brasil, século XIX" en Rinke, S y González, D. (orgs.), Expert knowledge in Latin American history: local transnational and global perspectives, Stuttgart, Heinz-Dieter Heinz, pp. 15-36.

Manchester, A. (1973): Preeminência inglesa do Brasil, São Paulo, Editora Brasiliense.

Miranda, J. A. R. (2013): Diplomata mais amante do seu paiz que das suas commodidades: a atuação de Francisco Adolfo de Varnhagen nas repúblicas do Pacífico (1863-1865), Dissertação de Mestrado, Pontifícia Universidade Católica do Rio Grande do Sul PUCRS, Porto Alegre.

Moraes, E. (1977): "O Manifesto Republicano de 1870", Revista de Ciencia Política, 20(4) 93-118. 
Paquette, G. (2018): "Império e nação nas monarquias constitucionais portuguesa e brasileira" en Ramos, R., Carvalho, J. M. y Silva, I., A monarquia constitucional dos Braganças em Portugal e no Brasil (1822-1910) Dois países, um Sistema, Lisboa, Dom Quixote, pp. 34-56.

Santos, L. C. V. (2004): O Brasil entre a América e a Europa: o Império e o interamericanismo (do Congresso do Panamá à Conferência de Washington), São Paulo, Ed. UNESP.

- (2014): A América do Sul no discurso diplomático brasileiro, Brasília, FUNAG.

Seckinger, R. (1984): The Brazilian Monarchy and the South American Republics, 18221831, Baton Rouge, Louisiana State University Press.

Schultz, K (2006): "A era das revoluções e a transferência da corte portuguesa para o Rio de Janeiro (1790-1821)" en Malerba, J. (org.). A independência brasileira: nova dimensões, Rio de Janeiro, Editora da FGV, pp. 125-152.

Schwarcz, L. M. (1999): As barbas do Imperador, São Paulo, Companhia das Letras.

Silveira, H. G. (2003): Joaquim Nabuco e Oliveira Lima: faces de um paradigma ideológico da americanização nas relações internacionais do Brasil, Porto Alegre, EDIPUCRS.

Uruguai, P. J. (2002): "Ensaio sobre o direito Administrativo" en Carvalho, J. M. (org.), Visconde do Uruguai, São Paulo, Editora 34, pp. 67-537.

Vázquez, J. Z. (2003): "Relaciones interamericanas e intervencionismo" en Vázquez, J. Z. (org.). Historia General de América Latina, Madrid, Ediciones UNESCO/Editorial Trotta, vol. 6, pp. 501-522. 